\title{
Research on the Stability Evaluation Model of Composite Support Pillar in Backfill-Strip Mining
}

\author{
Xiaojun Zhu $\mathbb{D}^{1,2}$ Guangli Guo $\mathbb{D}^{2}{ }^{2}$ Hui Liu $\mathbb{D}^{1,3}$ Xueni Peng, ${ }^{1}$ and Xiaoyu Yang ${ }^{4}$ \\ ${ }^{1}$ Anhui Province Engineering Laboratory for Mine Ecological Remediation, Anhui University, Hefei, China \\ ${ }^{2}$ School of Environment Science and Spatial Information, China University of Mining and Technology, Xuzhou, China \\ ${ }^{3}$ State Key Laboratory of Coal Resource and Safe Mining, China University of Mining and Technology, Xuzhou, China \\ ${ }^{4}$ Department of Engineering Management, Hefei College of Finance and Economics, Hefei, China
}

Correspondence should be addressed to Xiaojun Zhu; zhuxiaojunahu@126.com and Hui Liu; lhui99@aliyun.com

Received 6 August 2019; Accepted 21 January 2020; Published 18 February 2020

Academic Editor: Zhengbiao Peng

Copyright ( $\odot 2020$ Xiaojun Zhu et al. This is an open access article distributed under the Creative Commons Attribution License, which permits unrestricted use, distribution, and reproduction in any medium, provided the original work is properly cited.

\begin{abstract}
Backfill-strip mining, which combines the advantages of strip mining and backfill mining, is proposed to overcome high cost and shortage of filling materials in coal mines at present. The composite support pillar (CSP) is a combined support pillar of the filling body and coal pillar for supporting the overlying strata and achieving subsidence control. The stability of CSP is the key to the success of subsidence control in backfill-strip mining engineering. A stability evaluation model of the CSP mechanical model was proposed. First, the lateral stress between the coal pillar and filling body is calculated in consideration of their interaction relation in CSP based on the earth pressure theory. Then, the width calculation models of the broken and plastic zones of three types of CSPs are established on the basis of limit equilibrium theory. On this basis, the mathematical model of the safety design width of the three types of CSPs is proposed to ensure the stability of CSP. Meanwhile, an engineering case of stability width design of CSP is shown. This study can provide theoretical reference and technical support for the engineering design of backfill-strip mining.
\end{abstract}

\section{Introduction}

Coal resources are regarded as an important factor in the development of the world economy. The consumption of coal, which is a conventional fuel, has continuously increased in recent decades. However, intensive and massive coal mining brings a series of severe social and environmental problems, such as land subsidence, building damage, ground fissures, and landslides [1-3]. Among these problems, coal mining subsidence considerably impacts the environment and societies. Excavation of coal produces large voids in the coal seam and disturbs the equilibrium of the original internal stress in the surrounding rock strata. This condition leads to overlying strata bending and breaking, which result in surface subsidence. Surface subsidence can lead to damage of infrastructures, buildings, roads, and drainage systems [4]. Statistical data have shown that the mining subsidence area in China is around $6 \times 10^{3} \mathrm{~km}^{2}$ and the mining subsidence area expands by approximately $240 \mathrm{~km}^{2}$ annually [5]. Furthermore, the land subsidence area in China due to coal mining is larger than $20,000 \mathrm{~km}^{2}$ by 2017 [6]. Moreover, a large area of land subsidence has caused building damage and land abandonment, which have seriously affected the sustainable development. Therefore, several coal mining technologies have been proposed to control surface subsidence gradually for achieving coordinated and sustainable development of coal resource extraction and environmental protection.

At present, the surface subsidence control technologies can be divided into two categories [7]: backfilling mining (gob, caving zone, and separated-bed filling mining) and partial mining (strip mining and room-and-pillar mining). However, backfilling mining has the problems of high backfill cost, filling material shortage, and low backfill efficiency [8]. Meanwhile, partial mining wastes a large amount of coal resources because its coal resource recovery rate is too low [9]. Thus, backfill-strip mining technology $[10,11]$ is proposed to control surface subsidence for extracting coal resources under buildings, water bodies, and railways and improve the environment of the coal mining 
areas for solving the problems of high cost of backfilling mining and low recovery rate of partial mining. Backfill-strip mining is a partial filling mining method that integrates the advantages of strip mining and backfilling mining to control the movement of rock strata. In this mining technology, only part of the goaf space is filled by filling materials (Figure 1). This mining process eventually forms a combined support pillar (CSP) of the filling body and coal pillar for supporting the overlying strata. The increase in environmental constraints has made the advantages of backfill-strip mining increasingly prominent and facilitated its application in several coal mines in China [12-14], such as Daizhuang Coal Mine, Fucun Coal Mine, Xuchang Coal Mine, Xingdong Mining, and Handan Coal Mine.

The stability of CSP is the key to the success of backfillstrip mining. The stability of CSP means that CSP does not collapse completely after a long time and influence the surrounding mining actions, the effect of subsidence control of backfill-strip mining is good, and only a small number of cracks or even partial collapse occur in some positions of CSP. If CSP is failure, it may introduce violent secondary ground collapses and destroy the safety of ground surface structures and the environmental health state of the surrounding mining areas. Therefore, it is important to evaluate the stability of CSP to prevent subsidence disasters in the design stage of backfill-strip mining.

In backfill-strip mining, CSP is composed of the coal pillar and the filling body and a main support of the overlying strata. It is similar to the strip coal pillars of partial mining in terms of the stress distribution and deformation characteristics, and they both support the overlying strata and control surface subsidence with strip support pillars. Since about 1900, many investigators have studied the analysis of coal pillar stability in partial mining. From these studies, A.H. Wilson theory, tributary area theory, and pressure arch theory [15] have been developed to estimate pillar load. Different mathematical empirical formulas [16, 17], such as Salamon-Munro, Holland-Gaddy, and Obert-Duvall, have also been proposed to estimate coal pillar strength. A stability factor [16], which is calculated by comparing the load to the load-bearing capacity of the coal pillar system, has been proposed as well to estimate coal pillar stability. However, CSP is a multimedia complex structure and composed of coal pillars and the filling body. The mechanical properties of CSP are quite different from those of the coal pillar. The difference makes the stability calculation formula of the coal pillar incompletely applicable to CSP.

Many scholars $[18,19]$ have studied the mechanical properties of CSP to determine the movement deformation and mechanical properties of CSP in backfill-strip mining by a large number of mechanical and numerical simulation experiments. These scholars have believed the existence of cooperation support for the coal pillar and filling body in CSP. The coal pillars act as retaining walls, and the additional strength that the coal pillar provides to the filling body is imparted as a horizontal pressure along the sides of the filling body. The coal pillar can effectively improve the stress conditions of the filling body, enhance the stability of composite support system, and synergistically bear with the load of overlying strata [20]. On this basis, the deformation and failure characteristics of CSP under different influencing factors [21], such as geological mining conditions, filling techniques, coal pillar width, and filling body width, have been studied by numerical simulation. However, only a few stability calculation models of CSP are available. As a result, no effective scientific and mechanical formula can be used to evaluate the stability of CSP in the design stage of backfillstrip mining. Therefore, a mathematical model of the stability evaluation of CSP will be developed, which can provide theoretical reference and technical support for the engineering design of backfill-strip mining.

The rest of the paper is organized as follows. The classification and deformation characteristics of CSP are briefly introduced in Section 2. The width calculation models of the broken and plastic zones of three types of CSP are established on the basis of limit equilibrium theory and Coulomb criterion in Section 3. The safety width design methods of different types of CSP are proposed in Section 4 to ensure the stability of CSP. A calculation case of the stability analysis of CSP is shown in Section 5.

\section{Brief Overview on the Classification and Deformation Characteristics of CSP}

The mechanical properties of CSP need to be understood before establishing the stability model. The deformation characteristics and stress distribution of CSP have been studied through physical and numerical simulations [22-24]. Previous research has divided CSP into three parts, namely, broken zone, plastic zone, and elastic zone, according to different degrees of damage. Meanwhile, CSP is divided into three types, namely, Types I, II, and III, according to support characteristics and the width of broken, plastic, and elastic zones without considering the case of collapse or instability. The different types of features of CSP are discussed as follows.

The residual coal pillars in Type I CSP are wide (Figure 2). When the backfill-strip mining is completely extracted, the residual coal pillar and the filling body jointly bear the load of the overlying strata, the vertical stress on the coal pillar has four peaks, and the stress above the filling body is substantially equal to the original rock stress. At the same time, the coal pillar and backfill laterally restrict each other, and the coal pillar at the interface between the coal pillar and the filling body moves toward the center of the filling body. The coal pillar plays the role of a retaining wall by providing the lateral stress of the filling body to ensure its triaxial stress state and improved stability. The widths of the broken and plastic zones of Type I CSP are small, and its elastic zone, including partial coal pillars and all backfill bodies, is large. When solid backfilling technology is used in the backfill working face, the Type I CSP can be retained. It is difficult for solid filling material to support the overlying strata independently, but wide coal pillars can limit solid filling material from the side to ensure that the solid filling body does not collapse and has certain supporting capacity.

The residual coal pillars in Type II CSP are relatively narrow and are retained to control the deformation of the roadway and ensure that the filling body has sufficient time 


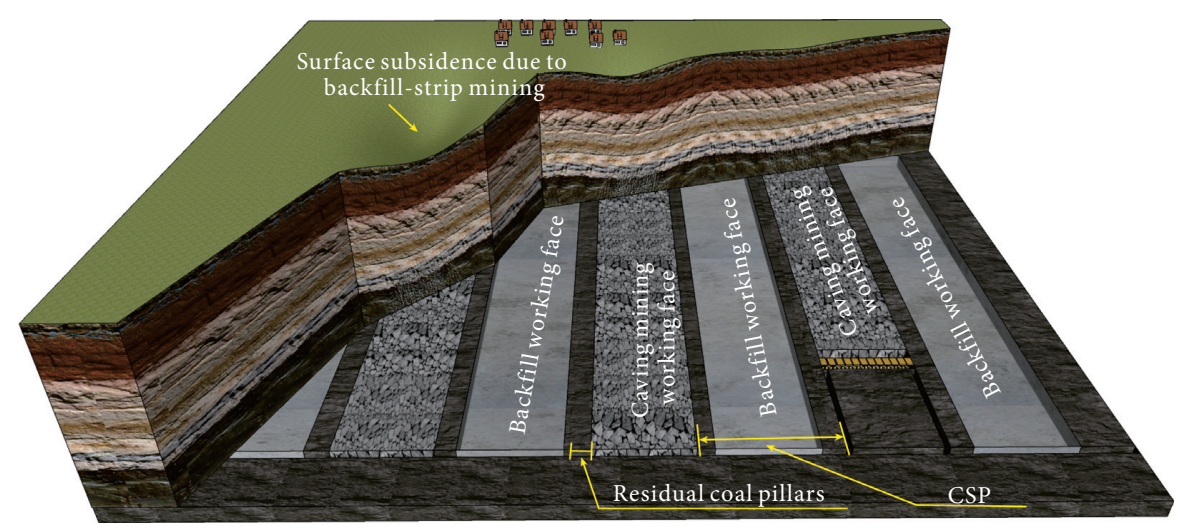

FIGURE 1: Diagram of backfill-strip mining.

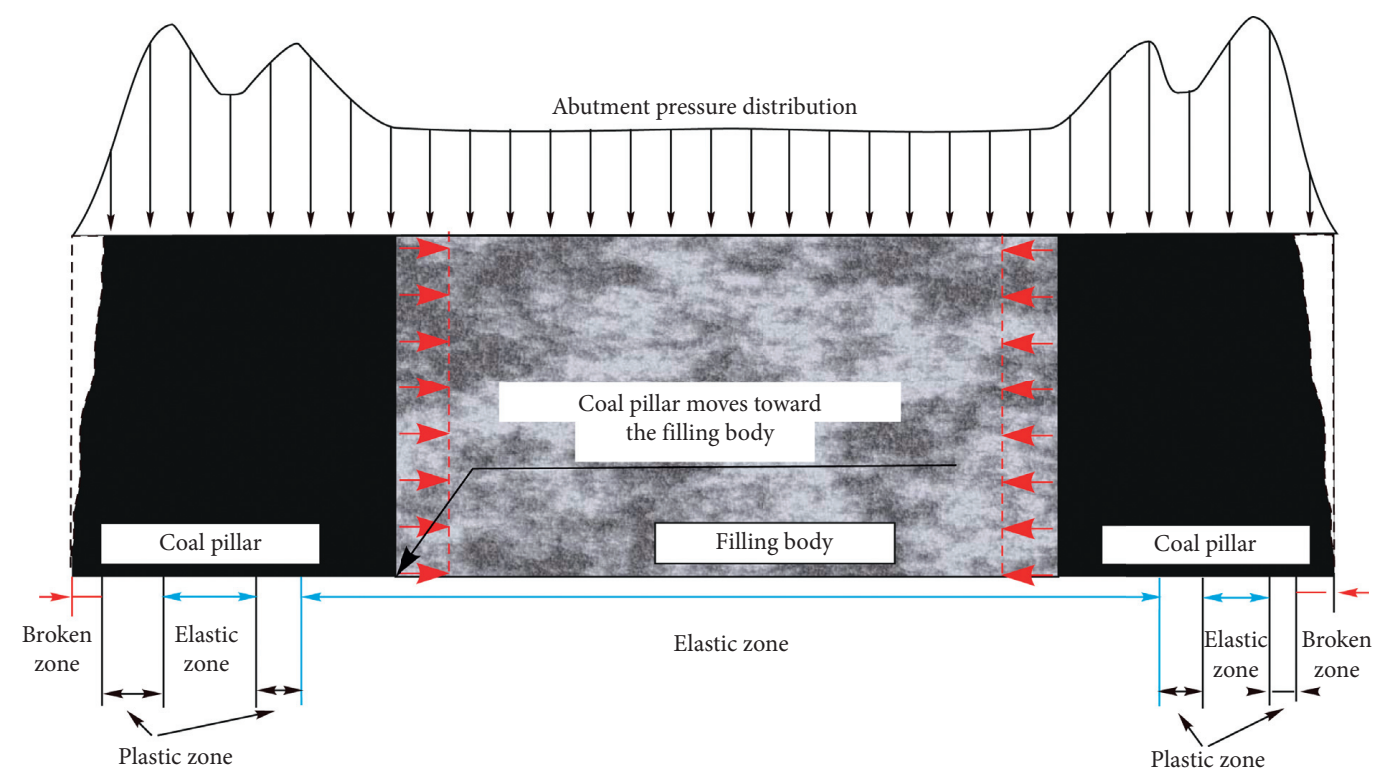

FIgure 2: Diagram of Type I CSP.

for compaction or solidification (Figure 3). Thus, the original four stress peaks are merged into two, two vertical stress peaks appear on the coal pillars, and the stress concentration is large. At the same time, the coal pillar still has lateral constraint on the filling body, and the coal pillar at the interface moves toward the center of the filling body. The widths of the broken and plastic zones of Type II CSP are larger than those of Type I CSP.

The residual coal pillars in Type III CSP completely collapse (Figure 4). The filling body is partially destroyed, but the CSP is intact. The abutment pressure of the coal pillars is smaller than the initial stresses, the vertical stress peak has transferred to the top of the filling body, and the load of the overlying strata is supported by the filling body. At the same time, the coal pillar has small or no lateral constraint on the filling body, and the filling body moves toward the goaf. When the Type III CSP is retained, the filling material cannot use solid filling material and can use the cement filling material, but the initial setting time and strength of the cement filling material have higher requirements in the Type III CSP.

\section{Stability Mechanical Model of CSP}

The stability of CSP is the key to the success of subsidence control of backfill-strip mining. The deformation characteristics, stress distribution, and failure behavior of CSP are studied to provide theoretical reference for the stability evaluation of CSP.

The residual coal pillars in Type II CSP are relatively narrow. As a result, the original four stress peaks in Type II CSP are merged into two, and the stress concentration is very large. No elastic zone appears in the middle of the residual coal pillar, and the coal pillar is full of plastic zones. In this state, the coal pillars continuously collapse in the form of creep, and the support capacity continues to decline. The stress peaks gradually transfer to the filling body, and Type II CSP finally evolves into Type III CSP. In the final state, Type II and Type III CSPs support the overlying strata only by the filling body. At this time, the filling body is adjacent to the goaf and no or small coal pillars laterally restrain on both sides. Partially broken and plastic zones appear on both sides of the filling body. Consequently, the 


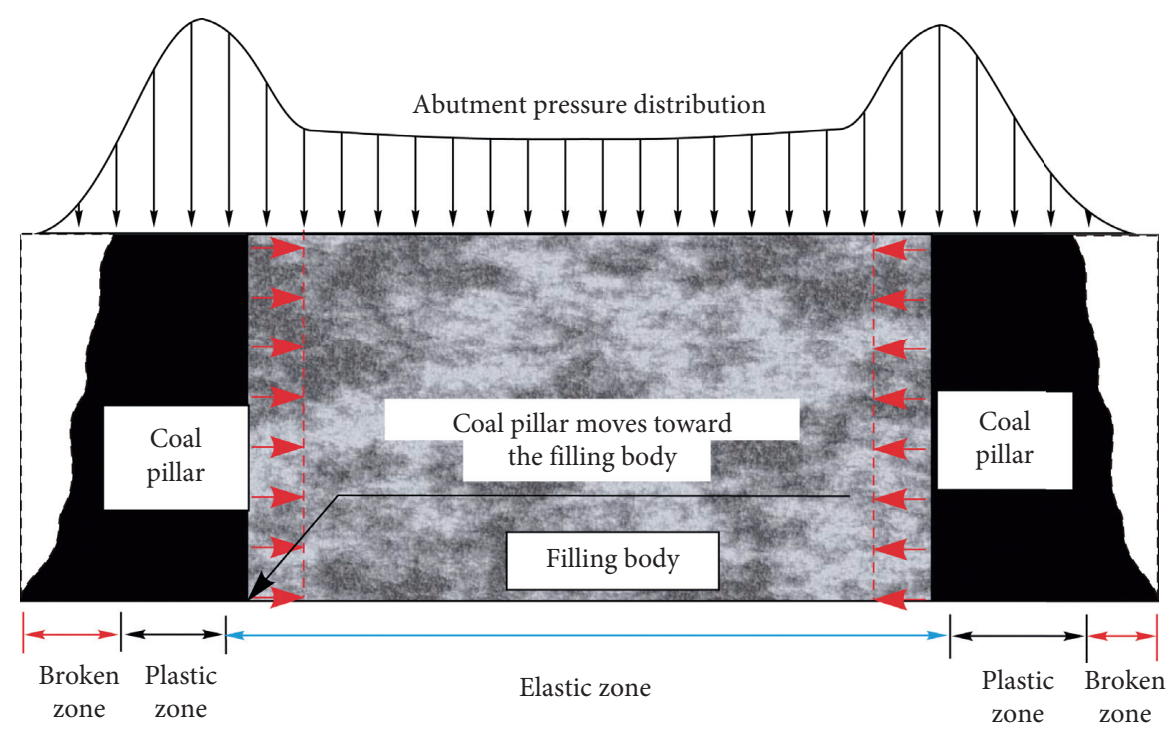

FIgURE 3: Diagram of Type II CSP.

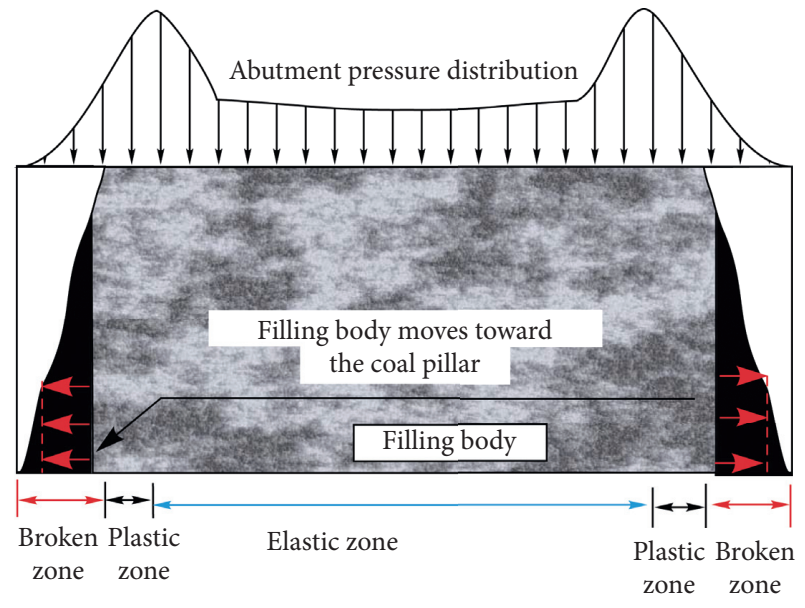

Figure 4: Diagram of Type III CSP.

coal pillar of Type II and Type III CSPs collapses, and the distribution of the elastic and plastic zones of the filling body only needs to be analyzed to evaluate the stability of CSP. However, the coal pillar in Type I CSP is wide, and the coal pillar and the filling body jointly bear the load of the overburden strata. Accordingly, the stability of the coal pillar and filling body needs to be analyzed. Therefore, the stability mathematical model of CSP is divided into two types in this section due to the different support forms of CSP.

CSP is a multimedia complex structure and has mechanical properties that are quite different from those of coal pillar. Therefore, the stability mechanical model of CSP cannot fully refer to that of the coal pillar. Figure 5 shows the flowchart of the stability evaluation of different CSPs. The establishment of the mechanical model of Type I CSP is divided into three steps. First, the lateral stress formulas of different types of CSP between the coal pillar and filling body are established on the basis of earth pressure theory to consider the interaction relation between the coal pillar and the filling body. Then, the width calculation models of the

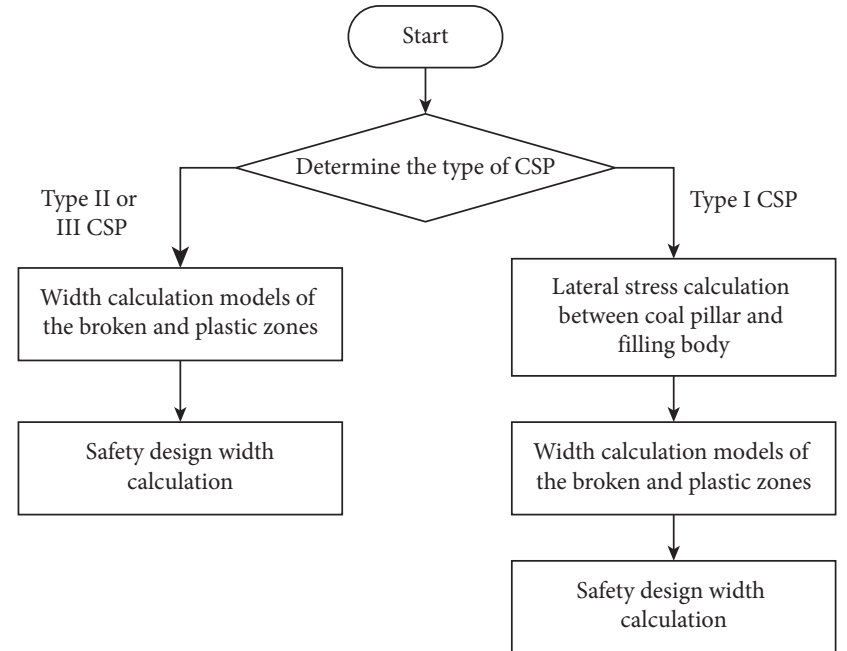

FIGURE 5: Flowchart of the stability evaluation of CSP.

broken and plastic zones of three types of CSP are established on the basis of limit equilibrium theory and Coulomb criterion. Finally, the safety width design methods of different types of CSP are proposed in consideration of the load-bearing capacities of the coal pillar and filling body. However, the coal pillar of Type II or III CSP is narrow, the coal pillars continuously collapse in the form of creep, and the lateral stress of the coal pillar to the filling body is small, so the lateral stress between the coal pillar and filling body does not need to be calculated in the establishment steps of the mechanical model of Type II or III CSP.

\subsection{Stability Mechanical Model of Type II and Type III CSPs.} In the final state, Type II and Type III CSPs support the overlying strata only by the filling body, and the coal pillar collapses and cannot support the filling body laterally. Thus, the stress between coal pillar and backfill does not need to be considered in the stability analysis of Type II and Type III 
CSPs. The establishment of the mechanical model of Type II and Type III CSPs is one less step than that of Type I CSP.

The width of the filling body has certain requirements during the design process of CSP to ensure the stability of the overall Type II and Type III CSPs. (1) The width of the filling body should be greater than the sum of the calculated width of the plastic and broken zones to prevent plastic zone communication on both sides of the filling body and prevent the filling body from losing the support capacity. (2) The filling body has sufficient strength to support the total load of the overburden strata. The safety dimension design process of Type II or III CSP is discussed as follows.

\subsubsection{Mechanical Formula of the Elastic and Plastic Zones of} Type II and Type III CSPs. The filling body is composed of complex mechanical materials. The mechanical behavior of these materials cannot be described using a unified constitutive equation. A large number of laboratory tests [25] showed the Coulomb failure criterion is generally suitable for the constitutive behavior of the filling body. So, the Coulomb criterion can be applied to the mechanical model of CSP. Meanwhile, four assumptions are required to apply the limit equilibrium theory and Coulomb criterion in small deformation elastoplastic theory for deriving the width calculation formula of the elastic and plastic zones. (1) The lateral filling body provides sufficient lateral restraint to the central filling body, and the central filling body is in an elastic state. (2) The filling body is only affected by the gravity stress of overlying strata but not by the tectonic stress. (3) The plastic zone is destroyed by shear stress, and the shear failure surface is parallel to coal seam. (4) The deformation of the filling body is small before the failure of the filling body.

In the model (Figure 6), $L_{0}$ is the limit equilibrium width, $m$ is the coal seam thickness, $P_{x}$ is the lateral binding force of the broken coal pillar on the filling body in the horizontal direction, $k_{1}$ is the stress concentration coefficient on the filling body, and $\tau_{z x}$ is the shear force between the filling body and the top and bottom plates.

The limit equilibrium width of the backfill is the sum of the broken and plastic zones. The formula is

$$
L_{0}=L_{s}+L_{p}
$$

where $L_{s}$ is the width of the broken zone and $L_{p}$ is the width of the plastic zone.

First, the limit equilibrium zone of the outer filling body with a width of $L_{0}$ is taken as the research object, and the balance equation between the plastic and elastic zones is

$$
\begin{aligned}
& \frac{\partial \sigma_{x}}{\partial x}+\frac{\partial \tau_{z x}}{\partial z}=0 \\
& \frac{\partial \tau_{z x}}{\partial x}+\frac{\partial \sigma_{z}}{\partial z}=0
\end{aligned}
$$

According to the limit equilibrium condition, the shear force of the slip surface in the filling body is

$$
\tau_{z x}=-\left(\sigma_{z} \tan \varphi_{0}+C_{0}\right) \text {, }
$$

where $\varphi_{0}$ is the internal friction angle of the filling body and $C_{0}$ is the cohesion of the filling body.

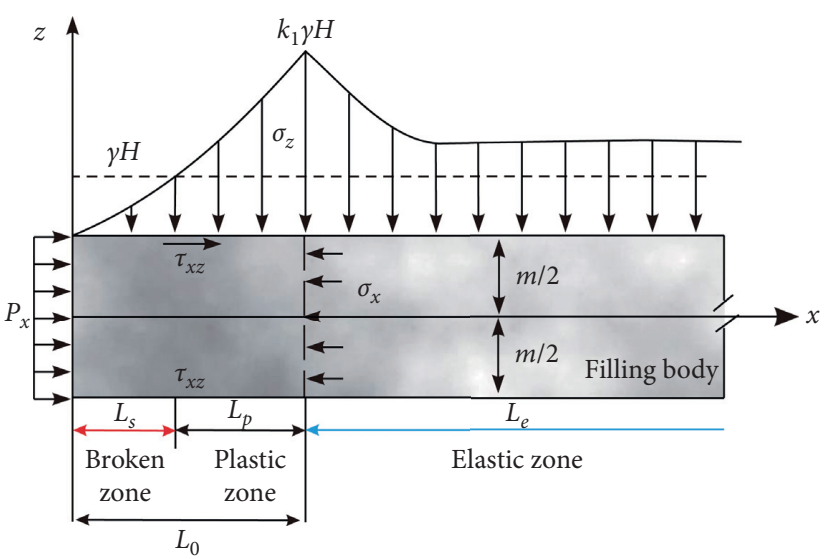

Figure 6: Schematic of the mechanical calculation model of Type II and Type III CSPs.

The stress boundary conditions are

$$
\left\{\begin{array}{l}
\text { when } x=0, \quad \sigma_{x}=P_{x}, \sigma_{z}=\frac{p_{x}}{\beta}, \\
\text { when } x=L_{0}, \quad \sigma_{x}=\beta k_{1} \gamma H, \sigma_{z}=k_{1} \gamma H,
\end{array}\right.
$$

where $\beta$ is the lateral pressure coefficient of the filling body, $\gamma$ is the average bulk density of the overlying strata, and $H$ is the average depth of coal seam.

So, the stress of the filling body on the equilibrium boundary can be obtained by substituting the limit equilibrium condition (equations (2) and (3)) into the stress bounding condition (equation (4)). The detailed derivation process can be referred to the literature $[26,27]$ :

$$
\left\{\begin{array}{l}
\sigma_{z}=\left(C_{0} \cot \varphi_{0}+\frac{P_{x}}{\beta}\right) e^{2 x \tan \varphi_{0} /(m \beta)}-C_{0} \cot \varphi_{0}, \\
\tau_{z x}=-\left(C_{0}+\frac{P_{x} \tan \varphi_{0}}{\beta}\right) e^{2 x \tan \varphi_{0} /(m \beta)} .
\end{array}\right.
$$

The limit equilibrium width of filling body is

$$
L_{0}=\frac{\beta m}{2 \tan \varphi_{0}} \ln \left(\frac{k_{1} \gamma H+C_{0} \cot \varphi_{0}}{P_{x} / \beta+C_{0} \cot \varphi_{0}}\right)+\left(\frac{m}{2}-|z|\right) \tan \varphi_{0} .
$$

As shown in equation (6), the limit equilibrium width of the filling body $\left(L_{0}\right)$ with different heights is unequal. $L_{0}$ between the upper and lower interfaces of filling body is small, and $L_{0}$ on the neutral surface of the filling body (that is, $z=0$ ) is large. If $z=0$, then the limit equilibrium width of the retained coal pillar is

$$
L_{0}=\frac{m}{2 \tan \varphi_{0}}\left[\ln \left(\frac{k_{1} \gamma H+C_{0} \cot \varphi_{0}}{P_{x} / \beta+C_{0} \cot \varphi_{0}}\right)^{\beta}+\tan ^{2} \varphi_{0}\right] .
$$

The widths of the broken zone and the plastic zone of coal pillar are different because of the different lateral stress. There are two possible scenarios for the width calculation of the plastic zone. When the lateral support is 
large enough, the coal pillar under the load of overlying strata only has plastic deformation and no broken zone. So, the width of the plastic zone of the filling body can be calculated by $L_{p}=L_{0}$.

When the vertical stress exceeds the compressive strength of the filling body, the filling body is broken. Then, the vertical stress decreases below the original rock stress. The interface between the broken and plastic zones meets the following boundary conditions:

$$
\left.\sigma_{z}\right|_{x=L_{s}}=\gamma H
$$

After substituting equation (8) into equation (7), the width of broken zone of the filling body $L_{b}$ can be calculated by

$$
L_{b}=\frac{m}{2 \tan \varphi_{0}}\left[\ln \left(\frac{\gamma H+C_{0} \cot \varphi_{0}}{P_{x} / \beta+C_{0} \cot \varphi_{0}}\right)^{\beta}+\tan ^{2} \varphi_{0}\right]
$$

The width of the plastic zone of the filling body can be calculated by

$$
L_{p}=L_{0}-L_{b}
$$

These width equations of the broken and plastic zones of filling body provide the basis for the subsequent safety design of CSP.

When CSP is of Type II or III, the stability of coal pillar on both sides in the CSP is poor. Therefore, the residual coal pillars on both sides are considered to provide lateral pressure for the filling body and reduce the plastic zone width of the filling body in the stability evaluation process of Type II or III CSP. The width of residual coal pillars does not participate in the safety dimension design calculation of CSP.

\subsubsection{Safety Design Width of Type II and Type III CSPs} Calculated by Crushing Load. The key of the stability of Type II and Type III CSPs is whether they can bear the load of the overlying strata. Thus, the load of the overlying strata and the load-bearing capacities of the filling body will be considered in the process of analyzing the safety width of the filling body.

Mark [28] used a concept of abutment angle $(\delta)$ to estimate the abutment load during final extraction of coal, which is known as "Analysis of Longwall Pillar Stability" (ALPS) and is used widely for designing of pillars in longwall gate roads. It can be seen from Figures 2-4 that the coal pillar is similar to the CSP in the support structure. Meanwhile, the research [29] on the distribution stress of the CSP has shown that the equivalent load carried by CSP is similar to the load carried by the coal pillar in the strip mining. Therefore, the concept of abutment angle is introduced into the calculation of the load on CSP, and the loading capacity of CSP can be simplified as shown in Figure 7. When backfill-strip mining is completed, the self-weight of the overlying strata of goaf will transfer to the CSP. As a result, the total load on the CSP is equal to the sum of the self-weight of the overlying strata above the CSP and the half the self-weight of the overlying strata above the goaf.

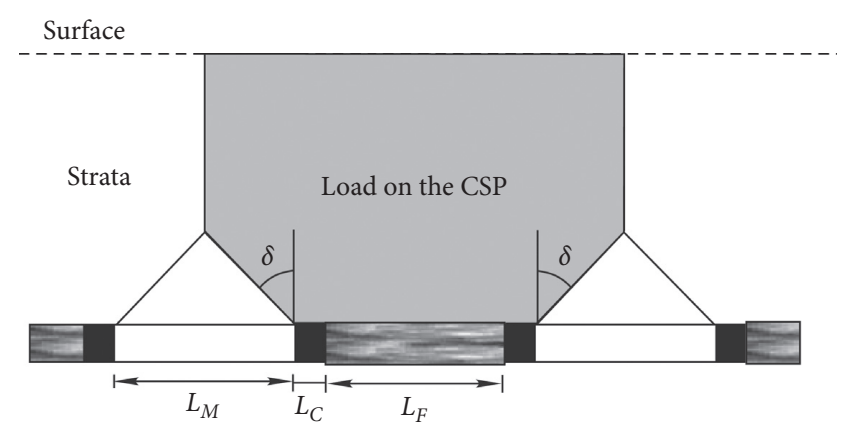

FIgURE 7: Equivalent support load of CSP.

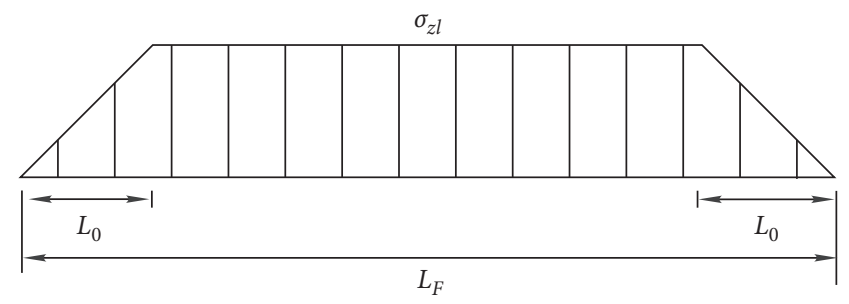

FIGURE 8: Bearing capacity of the filling body at different positions.

The load on CSP can be given by

$$
P=\gamma\left[\left(L_{F}+2 L_{C}+L_{M}\right) H-\frac{L_{M}^{2} \cot \delta}{4}\right],
$$

where $L_{F}$ is the width of filling body, $L_{C}$ is the width of the residual coal pillar for one side, $L_{M}$ is the width of caving mining working face or goaf, and $\delta$ is the abutment angle.

The overburden load on the filling body damages its edge and generates the broken and plastic zones on the edge. Consequently, the bearing capacity of the filling body at different positions varies. The bearing capacity of the filling body at different locations is assumed to be simplified into saddle shape to facilitate subsequent calculations. The bearing capacity rises linearly from 0 at the edge of filling body to the limit bearing capacity of filling body $\sigma_{z l}$ in the elastic zone and keeps the limit bearing capacity $\sigma_{z l}$ unchanged in the elastic zone (Figure 8). The limit bearing capacity $\sigma_{z l}$ is the upper limit of the ultimate stress at the peak point of stress distribution and is equal to $k_{1} \gamma H$, as shown in Figure 6.

The total load that can be carried by the filling body is

$$
P_{1}=\frac{2 L_{0} \times \sigma_{z l}}{2+\left(L_{F}-2 L_{0}\right) \sigma_{z l}}=k_{1}\left(L_{F}-L_{0}\right) \gamma H .
$$

When the filling body can carry the load and has minimum width, equation (11) is equal to equation (12). Thus, the minimum width of the filling body $L_{F \text { min }}$ is calculated by

$$
L_{F \min }=\frac{k_{1} \gamma H L_{0}+\gamma H\left(2 L_{C}+L_{M}\right)-\gamma L_{M}^{2} \cot \delta / 4}{\sigma_{z l}-\gamma H} .
$$

The limit equilibrium width $L_{0}$ calculated by using equation (7) and the limit bearing capacity of filling body $\sigma_{z l}$ 
are substituted into equation (13). The safety width of the filling body $L_{F \min }$ in Type II or III CSP is

$$
L_{F \min } \geq \frac{\left(k_{1} m \gamma H\right) /\left(2 \tan \varphi_{0}\right)\left[\ln \left(\left(k_{1} \gamma H+C_{0} \cot \varphi_{0}\right) /\left(P_{x} / \beta+C_{0} \cot \varphi_{0}\right)\right)^{\beta}+\tan ^{2} \varphi_{0}\right]+\gamma H\left(2 L_{c}+L_{M}\right)-\gamma L_{M}^{2} \cot \delta / 4}{k_{1} \gamma H-\gamma H} .
$$

For practical engineering safety, equation (14) needs to be multiplied by a safety factor $n$. The safety design width of filling body $L_{F}$ in Type II or III CSP is

$$
L_{F} \geq n \cdot \frac{\left(k_{1} m \gamma H\right) /\left(2 \tan \varphi_{0}\right)\left[\ln \left(\left(k_{1} \gamma H+C_{0} \cot \varphi_{0}\right) /\left(P_{x} / \beta+C_{0} \cot \varphi_{0}\right)\right)^{\beta}+\tan ^{2} \varphi_{0}\right]+\gamma H\left(2 L_{C}+L_{M}\right)-\gamma L_{M}^{2} \cot \delta / 4}{k_{1} \gamma H-\gamma H}
$$

where $n$ is a safety factor, which is greater than 1.5 in practical engineering.

3.2. Stability Mechanical Model of Type I CSP. The coal pillar in Type I CSP has a large width. As a result, the concentrated stress is collected on the residual coal pillars on both sides, and two stress peaks are formed on each side of the coal pillar. Meanwhile, the plastic zone appears on both sides of the coal pillar near the goaf and the filling body. The filling body has no lateral restraint. Thus, the plastic zone width of the coal pillar near the goaf is large, and the broken zone appears. Nevertheless, an elastic zone still appears in the coal pillar, and the coal pillar is stable. Therefore, the coal pillars and the lateral restraint between the coal pillars and the backfill cannot be ignored in the stability analysis of Type II and Type III CSPs.

In the establishment of mechanical model of Type I CSP, the lateral stress between the coal pillar and filling body needs to be calculated first. Then, the width of the broken and plastic zones of the coal pillar is analyzed by the limit equilibrium method. This analysis can be referred to the previous analysis formula of the filling body of Type II and Type III CSPs. Finally, the safety width of the filling body is analyzed in consideration of the load-bearing capacities of the coal pillar and filling body.

3.2.1. Lateral Stress Calculation between Coal Pillar and Filling Body. When the backfill-strip mining is completed, the filling body reaches the final strength, and the lateral restraint is formed between the coal pillar and the filling body. The lateral stress generated by the coal pillar on the filling body changes the stress state of the filling body from 2D to 3D.

The lateral earth pressure of coal pillar on the filling body also varies in different types of CSP. Donavan earth pressure theory has been adopted to quantify the amount of lateral support provided by the filling body when the lateral earth pressure between coal pillars and filling body is studied [30]. The present work introduces this idea into the lateral earth pressure analysis between the coal pillar and filling body in CSP. The lateral action of the coal pillar on the filling body may be regarded as the action of the retaining wall. Earth pressure theory is used to analyze the lateral earth pressure between the coal pillar and filling body. The lateral earth pressure of the coal pillar on the filling body can be divided into active and passive lateral pressures.

When the width of the residual coal pillar in the Type I CSP is large, the coal pillar moves toward the filling body under the load of the overlying strata (Figure 2). In this case, the coal pillars act as retaining walls and the pressure acting on the coal pillar is passive lateral pressure.

According to Rankine earth pressure theory, the passive lateral pressure between the filling body and the coal pillar is calculated as follows:

$$
P_{b}=\gamma_{F} z K_{p}+2 C_{0} \cdot \sqrt{K_{p}}+q \cdot K_{p}
$$

where $P_{b}$ is the passive lateral pressure, $\gamma_{F}$ is the bulk density of the filling body, $z$ is the vertical distance from the top of the filling body to the calculation point, $q$ is the load applied to the filling body, and $K_{p}=\tan ^{2}\left(45^{\circ}+\varphi / 2\right)$ is the coefficient of passive lateral pressure.

3.2.2. Mechanical Formula of the Elastic and Plastic Zones of Type I CSP. The stability of Type I CSP can still be analyzed by the limit equilibrium method for the broken and plastic zones of coal pillar. The mechanical calculation model of Type I CSP is shown in Figure 9. When solid wastes (such as gangue, coal ash, and loess) are used as the filling material, the width of the coal pillar should be wide. The CSP tends to adopt Type I because nearly no cohesive force exists between the particles in the solid waste materials, and they have poor supporting capacity without lateral constraints. Therefore, the prerequisite for ensuring the stability of CSP is to guarantee the stability of the coal pillar. The width of the elastic and plastic zones of the coal pillar is calculated in this section.

The width of the broken zone in the coal pillar is

$$
L_{b}=\frac{m}{2 \tan \varphi_{0}}\left[\ln \left(\frac{\gamma H+C_{0} \cot \varphi_{0}}{P_{x} / \beta+C_{0} \cot \varphi_{0}}\right)^{\beta}+\tan ^{2} \varphi_{0}\right]
$$

The width of the plastic zone of the outer coal pillar is 


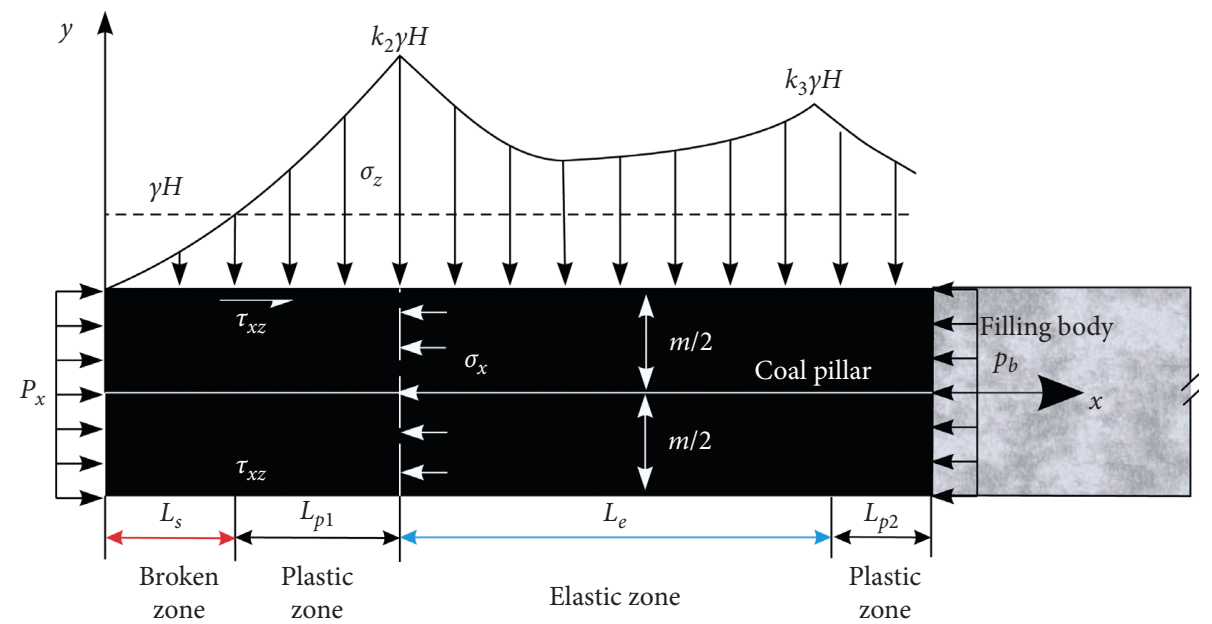

Figure 9: Schematic of the mechanical calculation model of Type I CSP.

$$
L_{p 1}=\frac{m}{2 \tan \varphi_{0}}\left[\ln \left(\frac{k_{2} \gamma H+C_{0} \cot \varphi_{0}}{P_{x} / \beta+C_{0} \cot \varphi_{0}}\right)^{\beta}+\tan ^{2} \varphi_{0}\right]-L_{b} .
$$

The width of the plastic zone of the internal coal pillar close to the filling body is

$$
L_{p 2}=\frac{m}{2 \tan \varphi_{0}}\left[\ln \left(\frac{k_{3} \gamma H+C_{0} \cot \varphi_{0}}{P_{b} / \beta+C_{0} \cot \varphi_{0}}\right)^{\beta}+\tan ^{2} \varphi_{0}\right],
$$

where $k_{2}$ is the stress concentration coefficient of the external coal pillar and $k_{3}$ is the stress concentration coefficient of the internal coal pillar close to the filling body.

The minimum width of the coal pillar $L_{M \text { min }}$ is equal to the width sum of the plastic and broken zones multiplied by a safety factor $n$ :

$$
\begin{aligned}
L_{M \min }= & n\left(L_{b}+L_{p 1}+L_{p 2}\right) \\
= & \frac{n \cdot m}{2 \tan \varphi_{0}}\left[\ln \left(\frac{k_{2} \gamma H+C_{0} \cot \varphi_{0}}{P_{x} / \beta+C_{0} \cot \varphi_{0}}\right)^{\beta}\right. \\
& \left.+\ln \left(\frac{k_{3} \gamma H+C_{0} \cot \varphi_{0}}{P_{x} / \beta+C_{0} \cot \varphi_{0}}\right)^{\beta}+2 \tan ^{2} \varphi_{0}\right] .
\end{aligned}
$$

3.2.3. Safety Design Width of Type I CSP Calculated by Crushing Load. The overburden load on the coal pillar of Type I CSP damages part of the coal pillar and generates broken and plastic zones. Consequently, the bearing capacity of Type I at different positions varies. On the basis of the stress distribution and elastic-plastic zone of Type I CSP (Figure 2), the bearing capacity of the CSP at different locations is assumed to be simplified into the shape shown in Figure 10 to facilitate subsequent calculations. The bearing capacity rises linearly from 0 at the edge of the filling body to the limit bearing capacity of coal pillar $k_{2} \gamma H$ in the elastic zone, decreases to $k_{1} \gamma H$ at the junction of coal pillar and filling body, and keeps the limit bearing capacity $k_{1} \gamma H$ unchanged in the filling body (Figure 10).

The load on Type I CSP can be given by

$$
\begin{aligned}
P_{1}= & 2\left(L_{b}+L_{p 1}\right) \frac{k_{2} \gamma H}{2}+2\left(L_{M}-L_{b}-L_{p 1}-L_{p 2}\right) k_{2} \gamma H \\
& +2 L_{p 2}\left(k_{1}+k_{2}\right) \frac{\gamma H}{2}+L_{F} k_{1} \gamma H \\
= & {\left[\left(2 L_{c}-L_{b}-L_{p 1}-L_{p 2}\right) k_{2}+\left(L_{p 2}+L_{F}\right) k_{1}\right] \gamma H . }
\end{aligned}
$$

When the filling body can carry the load and had minimum width, equation (11) is equal to equation (21). Thus, the minimum width of the filling body $L_{F \text { min }}$ is calculated by

$$
L_{F \min }=\frac{\left[L_{M}-2\left(k_{2}-1\right) L_{C}+k_{2} L_{b}+k_{2} L_{p 1}+\left(k_{2}-k_{1}\right) L_{p 2}\right]-L_{M}^{2} \cot \delta /(4 H)}{k_{1}-1} .
$$

The width of the broken zone in the coal pillar $L_{b}$ in equation (17) and the width of the plastic zone of the coal pillar $L_{p 1}$ in equation (18) and $L_{p 2}$ in equation (19) are substituted in equation (22). For practical engineering safety, 


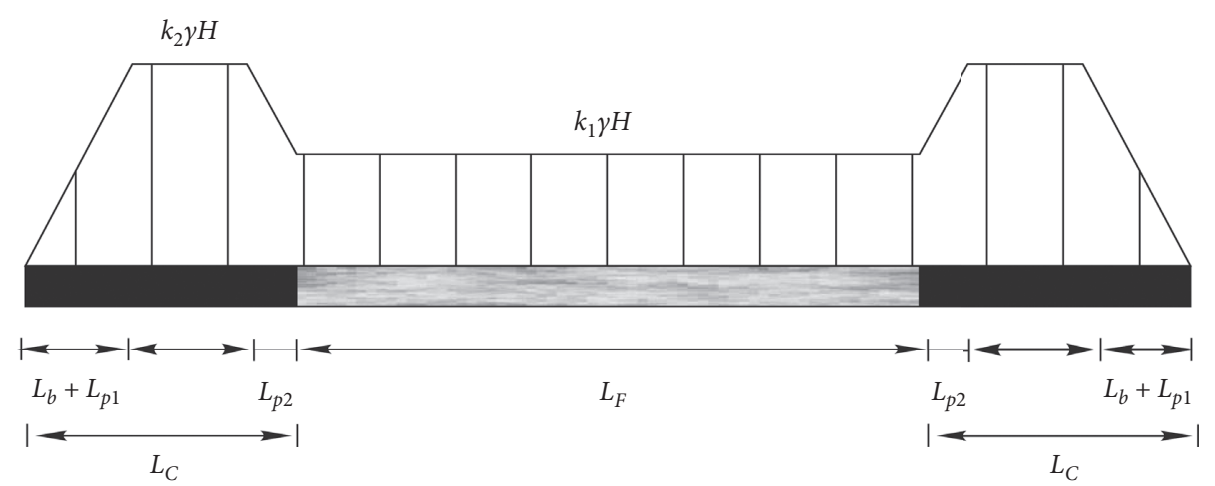

Figure 10: Bearing capacity of Type I at different positions.

equation (22) needs to be multiplied by a safety factor. The safety design width of filling body $L_{F}$ in Type I CSP is

$$
\begin{aligned}
L_{F \min }= & n \cdot \frac{L_{M}-2\left(k_{2}-1\right) L_{C}+\left(k_{2} m\right) /\left(2 \tan \varphi_{0}\right) \ln \left(\left(k_{2} \gamma H+C_{0} \cot \varphi_{0}\right) /\left(P_{x} / \beta+C_{0} \cot \varphi_{0}\right)\right)^{\beta}+\left(\left(k_{2}-k_{1}\right) m\right) /\left(2 \tan \varphi_{0}\right) \ln \left(\left(k_{3} \gamma H+C_{0} \cot \varphi_{0}\right) /\left(P_{b} / \beta+C_{0} \cot \varphi_{0}\right)\right)^{\beta}+m \tan \varphi_{0}}{k_{1}-1} \\
& -\frac{n \cdot L_{M}^{2} \cot \delta /(4 H)}{k_{1}-1},
\end{aligned}
$$

where $n$ is a safety factor, which is greater than 1.5 in practical engineering.

\section{Case of Stability Width Design of CSP}

Yangzhuang Coal Mine is located in Huaibei City, Anhui Province, China. Numerous residential buildings are located above this mining area. Statistics have shown that the recoverable coal reserves located under residential buildings are estimated at 20.8 million tons, thereby severely limiting the serving period of the coal mine. Backfilling mining technology has been applied in the original design of the coal mine to exploit the coal seam and prevent the damage of ground buildings. However, the filling cost is relatively high. If the buildings above the mining area will be relocated, then the relocation costs will be exceedingly high. Therefore, backfill-strip mining is attempted to extract coal resources under buildings and reduce filling cost. Type I CSP is designed to support the load of overlying strata for ensuring the safety of surface buildings and the subsidence control effect of the overlying strata. The average thickness of the coal seam is $2.7 \mathrm{~m}$, the mining depth of the backfill-strip mining working face is $410 \mathrm{~m}$, and the average bulk density of the overlying strata $\gamma$ is $27 \mathrm{kN} / \mathrm{m}^{3}$. When the backfill-strip mining is completed, the width of the goal on the both sides of CSP is $60 \mathrm{~m}$. The stress concentration coefficient of the retention coal pillar is 3.0, the internal friction angle of the coal seam interface $\varphi_{0}$ is $24^{\circ}$, and the bonding force of the coal seam interface $C_{0}$ is $1.2 \mathrm{MPa}$. The stress concentration coefficient on the filling body is 2.5 , and the lateral pressure coefficient is $\beta=\mu /(1-\mu)$. Poisson's ratio $\mu$ is $0.3, \beta=0.43$, and the safety coefficient $n$ is 1.5 .

In the process of designing the safety width of Type I CSP, the filling body is first assumed to have sufficient width to remain stable and provide sufficient lateral pressure on the coal pillar. Then, the safety width of the coal pillar in Type I CSP is calculated. On this basis, the safety width of the filling body is calculated. Finally, the safety width of CSP is equal to the width sum of the coal pillars and the filling body to ensure the stability of CSP.

4.1. Safety Width Calculation of the Coal Pillar. The supports in the goaf, such as meteorites and anchors, have no binding effect on the horizontal direction of the coal wall, and the lateral binding force from the goaf $P_{x}=0$. In accordance with equations (17) and (18), the widths of the broken and plastic zones in the external coal pillar can be calculated. The width of the broken zone in the coal pillar $L_{b}$ is $2.73 \mathrm{~m}$, and the width of the plastic zone of the outer coal pillar $L_{p 1}$ is $1.25 \mathrm{~m}$.

The passive lateral pressure between the filling body and the coal pillar $P_{b}=29.9 \mathrm{MPa}$ according to equation (16). Given the large lateral stress on the coal pillar, the width of the plastic zone of the internal coal pillar close to the filling body and the filling body $L_{p 2}$ is calculated to be equal to 0 .

The safety width of the coal pillar $L_{M} \geq n\left(L_{b}+L_{p 1}+\right.$ $\left.L_{p 2}\right) \approx 5.97 \mathrm{~m}$ according to the minimum width of the coal pillar (equation (20)) and the safety coefficient of the coal pillar.

Therefore, the width of the coal pillar on both sides is at least $6 \mathrm{~m}$ to ensure the stability of the coal pillar in Type I CSP.

4.2. Safety Width Calculation of the Filling Body. The safety width of the filling body $L_{F}$ can be calculated by using Eq. (22). The obtained safety coefficient of the filling body $L_{F} \geq 47.88 \mathrm{~m}$. 
4.3. Safety Design Width Calculation of Type ICSP. The width of the composite support should be greater than or equal to $59.8 \mathrm{~m}$ to ensure long-term stability of CSP under the aforementioned geological mining conditions.

\section{Conclusions}

The stability of CSP is the key to the success of subsidence control in backfill-strip mining. A stability evaluation model of the CSP mechanical model was proposed, and this model can be built in three steps. First, the lateral stress between the coal pillar and filling body is calculated in consideration of their interaction relation in CSP based on the earth pressure theory. Then, the width calculation models of the broken and plastic zones of three types of CSPs are established on the basis of limit equilibrium theory. On this basis, the mathematical model of the safety design width of the three types of CSP is proposed to ensure the stability of CSP. Meanwhile, the evaluation model of Type II and Type III CSPs has one less step than that of Type I CSP. This study can provide theoretical reference and technical support for the engineering design of backfill-strip mining.

\section{Data Availability}

The data used to support the findings of this study are available from the corresponding author upon request.

\section{Conflicts of Interest}

The authors declare that they have no conflicts of interest.

\section{Acknowledgments}

This work was supported by the National Natural Science Foundation of China (51804001), Natural Science Foundation of Anhui Province (1808085QE147), and Research Fund of the State Key Laboratory of Coal Resources and Safe Mining (SKLCRSM 15KF06).

\section{References}

[1] Z. Bian, X. Miao, S. Lei, S.-E. Chen, W. Wang, and S. Struthers, "The challenges of reusing mining and mineral-processing wastes," Science, vol. 337, no. 6095, pp. 702-703, 2012.

[2] Y. Chen, J. Zhang, A. Zhou, and B. Yin, "Modeling and analysis of mining subsidence disaster chains based on stochastic Petri nets," Natural Hazards, vol. 92, no. 1, pp. 19-41, 2018.

[3] E. F. Salmia, M. Nazemb, and M. Karakus, "Numerical analysis of a large landslide induced by coal mining subsidence," Engineering Geology, vol. 217, no. 1, pp. 141-152, 2017.

[4] D. Lamich, M. Marschalko, I. Yilmaz et al., "Subsidence measurements in roads and implementation in land use plan optimisation in areas affected by deep coal mining," Environmental Earth Sciences, vol. 75, no. 1, pp. 1-11, 2016.

[5] G. L. Guo, W. K. Feng, J. F. Zha, Y. X. Liu, and Q. Wang, "Subsidence control and farmland conservation by solid backfilling mining technology," Transactions of Nonferrous Metals Society of China, vol. 21, pp. 665-669, 2011.

[6] B. N. Hu and W. Guo, "Mining subsidence area status, syntheses governance model and governance recommendation," Coal Mining Technology, vol. 23, no. 2, pp. 1-4, 2018.
[7] S. Chen, D. Yin, F. Cao, Y. Liu, and K. Ren, "An overview of integrated surface subsidence-reducing technology in mining areas of China," Natural Hazards, vol. 81, no. 2, pp. 1129$1145,2016$.

[8] X. J. Zhu, G. L. Guo, J. F. Zha, T. Chen, Q. Fang, and X. Yang, "Surface dynamic subsidence prediction model of solid backfill mining," Environmental Earth Sciences, vol. 75, no. 12, pp. 1-9, 2016.

[9] E. Ghasemi, M. Ataei, and K. Shahriar, "An intelligent approach to predict pillar sizing in designing room and pillar coal mines," International Journal of Rock Mechanics and Mining Sciences, vol. 65, no. 2, pp. 86-95, 2014.

[10] S. J. Chen, W. J. Guo, H. Zhou, and G. H. Wen, "Structure model and movement law of overburden during strip pillar mining backfill with cream-body," Journal of China Coal Society, vol. 36, no. 7, pp. 1081-1086, 2011.

[11] J. L. Xu, Q. You, W. B. Zhu, X. S. Li, and W. Q. Lai, "Theoretical study of strip-filling to control mining subsidence," Journal of China Coal Society, vol. 32, no. 2, pp. 119-122, 2007.

[12] W. Cao, X. Wang, P. Li, D. Zhang, C. Sun, and D. Qin, "Wide strip backfill mining for surface subsidence control and its application in critical mining conditions of a coal mine," Sustainability, vol. 10, no. 3, p. 700, 2018.

[13] J. W. Bai, R. T. Liu, Y. J. Jiang et al., "Surrounding rock deformation and confined water upflowing law during stripfilling replacement mining," Journal of Mining and Safety Engineering, vol. 35, no. 2, pp. 352-358, 2018.

[14] W. Tang, X. Sun, H. Wang et al., "Study on effect of overlying strata stability during strip coal pillar excavation with paste backfilling," Coal Science and Technology, vol. 45, no. 9, pp. 109-115, 2017.

[15] H. Xie, D. Fabing, Z. Hongwei, and Z. Guoxu, "Recent developments of theory and analysis methods of strip pillar stability," China Mining Magazine, vol. 7, no. 5, pp. 37-41, 1998.

[16] C. Mark, "The evolution of intelligent coal pillar design: 1981-2006," in Proceedings of the 25th International Conference on Ground Control in Mining, Morgantown, WV, USA, August 2006.

[17] W. A. Hustrulid, "A review of coal pillar strength formulas," Rock Mechanics, vol. 8, no. 2, pp. 115-145, 1976.

[18] X. Zhu, G. Guo, H. Liu, T. Chen, and X. Yang, "Experimental research on strata movement characteristics of backfill-strip mining using similar material modeling," Bulletin of Engineering Geology and the Environment, vol. 78, no. 4, pp. 2151-2167, 2019.

[19] W. B. Xie, Z. F. Shi, X. X. Chen, and B. S. Zheng, "Analysis of surrounding rock activities in partial backfill mining," Journal of China University of Mining and Technology, vol. 33, no. 2, pp. 38-41, 2004.

[20] B. Hu and H. Li, "Numerical simulation study and mechanism analysis on backfill material in coal mine," Coal Science and Technology, vol. 38, no. 4, pp. 13-16, 2010.

[21] H. R. Liu, Numerical Simulation on Coal Pillar Stability and its Influencing Factors in Condition of Strip-Filling Mining, Northeastern University, Boston, MA, USA, 2008.

[22] X. J. Zhu, G. L. Guo, Z. Qian, and Q. Fang, "Simulation analysis of strata movement characteristics of backfill-strip mining," Journal of Mines, Metals and Fuels, vol. 63, no. 11, pp. 411-418, 2015.

[23] F. Wang, B. Jiang, S. Chen, and M. Ren, "Surface collapse control under thick unconsolidated layers by backfilling strip mining in coal mines," International Journal of Rock Mechanics and Mining Sciences, vol. 113, no. 1, pp. 268-277, 2019. 
[24] T. Zhao, S. Ma, and Z. Zhang, "Ground control monitoring in backfilled strip mining under the metropolitan district: case study," International Journal of Geomechanics, vol. 18, no. 7, pp. 1-14, 2018.

[25] B. Ercikdi, T. Yllmaz, and G. Külekci, "Strength and ultrasonic properties of cemented paste backfill," Ultrasonics, vol. 54, no. 1, pp. 195-204, 2014.

[26] C. Hou and N. Ma, "Stress in in-seam roadway sides and limit equilibrium zone," Journal of China Coal Society, vol. 4, no. 12, pp. 21-29, 1989.

[27] L. Wu and J. Wang, "Calculation of width of yielding zone of coal pillar and analysis of influencing factors," Journal of China Coal Society, vol. 20, no. 6, pp. 625-631, 1995.

[28] C. Mark, Analysis of Longwall Pillar Stability, Pennsylvania State University, State College, PA, USA, 1987.

[29] X. Zhu, G. Guo, X. Yang, and T. Chen, "Deformation characteristics and stress distribution of filling body and coal pillar in backfill-strip mining," Electronic Journal of Geotechnical Engineering, vol. 21, no. 6, pp. 455-466, 2016.

[30] J. G. Donovan and M. G. Karfakis, "Design of backfilled thinseam coal pillars using earth pressure theory," Geotechnical and Geological Engineering, vol. 22, no. 4, pp. 627-642, 2004. 